\section{Segundo Congreso Global de Investigación Cualitativa en Salud: ¿qué posición toma la Medicina?}

\section{Second Global Congress for Qualitative Health Research: What stand will Medicine take?}

Sr. Editor:

La investigación en medicina y cuidado de la salud está fuertemente dominada por el paradigma positivista. Los datos sobre los cuales se construye una impresión diagnóstica responden a preguntas -explícitas o no- del tipo: ¿qué edad tiene?, ¿cuánto pesa?, ¿desde cuándo tiene tos?, de uno a diez ¿cuánto le duele?, que luego son llevados a categorías mayores: ¿agudo o crónico?, ¿médico o quirúrgico? y aún a subcategorías relacionadas a la factibilidad de la etiología y al pronóstico de un cuadro en caso de tomar la decisión $x, y \mathrm{o} z$. Es así y se da por sentado que así es como debe ser. Las organizaciones de salud se configuran enteramente en base a esta forma de razonar, hecho acentuado por las dificultades para liberarse de un entorno sociopolítico efectista, mercantil.

No discutiremos si ésta es la forma más efectiva de canalizar el talento y preparación que un médico puede ofrecer. Sin embargo, es prudente reflexionar sobre el hecho de que el cuidado de la salud envuelve muchas dimensiones superpuestas, que permiten la comprensión de un ser humano integrado. Por ejemplo, la dimensión simbólica -que ha recibido poca atención en la investigación médica- aunque ha habido esfuerzos por organizar de manera sistemática la respuesta en salud, como es el caso de la medicina basada en la evidencia. De acuerdo a análisis recientes, metodologías como ésa tienen un alcance muy limitado, pues se enfocan en un orden de evidencias restringido ${ }^{1}$ y al reflejar también la lógica lineal de sesgo cartesiano no resultan particularmente iluminadoras para una transformación de orden epistémico en la noción de medicina y salud ${ }^{2}$.

En una arena contrapuesta, una aproximación cualitativa puede ofrecer una expansión significativa y reveladora en nuestra comprensión de los fenómenos de salud. Concerniente a esto, se han realizado ya dos versiones del Congreso Global de Investigación Cualitativa en Salud (Global Congress for Qualitative Health Research). Este año tuvo lugar en Milán la segunda edición del evento, en el que se presentaron más de doscientos trabajos (comunicaciones orales y "posters"), liderado por la Profesora Janice Morse (University of Utah), una referente indiscutible en la bibliografía sobre este tema ${ }^{3}$.

¿De qué manera contribuye la investigación cualitativa a los profesionales de la salud? Para quienes están más bien familiarizados con datos de tipo epidemiológico o clínico es necesario reconsiderar las categorías analíticas personales. La investigación cualitativa, en su sentido más íntimo y a riesgo de reduccionismo, reconoce datos no numéricos desde los que emergen ideas que, a la vez, permiten proponer nuevas hipótesis. Así, por ejemplo, en el congreso de Milán se presentaron estudios que podríamos agrupar en tres ejes: sujeto, interacción terapéutica y modelo de salud. Indicaremos algunos ejemplos temáticos.

1. Eje Sujeto: Estigma en salud, patrones de conductas en el beber; narrativas biográficas de sobrevivientes a abuso y violación; involucramiento en personas con limitaciones intelectuales; procesos personales de afrontamiento y adaptación; dinámicas en hogares para personas con demencia; experiencias sobre el envejecimiento, el sufrimiento y la muerte.

2. Eje Interacción Terapéutica: Construcción del rol de paciente; transformación social y aprendizaje interprofesional en las ocupaciones de salud; tecnologías de la comunicación en el soporte emocional; procesos de convocatoria a ensayos clínicos; co-construcción de terapias grupales.

3. Eje Modelo de Salud: Discursos dominantes; reconceptualización de problemas de salud; procesos de toma de decisiones; generación de nuevas teorías y dispositivos metodológicos; procesos en docencia clínica.

Otros, como el presentado por estos autores, se relacionan con discusiones epistémicas y metodológicas que reabren un debate sobre las corrientes dominantes y las no convencionales en investigación cualitativa.

La exploración de estos tópicos, interesante en la esfera teórico-metodológica, es de relevancia en el ámbito terapéutico y en la concepción y remodelación de los sistemas de salud. Es necesario que el médico, pieza clave en los fenómenos sociopolíticos relativos a salud y bienestar, logre mayor involucramiento tanto en el planteamiento de problemas de naturaleza cualitativa, como en la ampliación de sus recursos metodológicos que den respuesta a este tipo de problemas de investigación. 
El Tercer Congreso Global, que se realizará en diciembre de 2013 en Khon Kaen, Tailandia (http://global-qhr.org/), estará consagrado al holismo en salud y al valor de las evidencias que aporta la investigación cualitativa. Ésta será una oportunidad para vitalizar el involucramiento necesario en el pensamiento cualitativo y definir una posición para la medicina en esta área. Un compromiso de esta naturaleza será importante para balancear las fuerzas del paradigma positivista, $\tan$ arraigadas en las nociones de medicina, salud y cuidado.

\section{Ricardo A. Ayala ${ }^{1}$ Tomás F. Koch ${ }^{2}$} ${ }^{1}$ Department of Sociology, Ghent University, Bélgica.

${ }^{2}$ Escuela de Sociología, Universidad de Playa Ancha. Valparaíso, Chile.

\section{Referencias}

1. Walsh B., Gillett G. Is Evidence-based Medicine positivist? Int J Pers Cent Med 2011; 1 (2): 232-9.

2. Djulbegovic B, Guyatt GH, Ashcroft RE. Epistemologic inquiries in evidence-based medicine. Cancer Control 2009; 16 (2): 158-68.

3. Morse J. Critical Issues in Qualitative Research Methods. 1994. California: Sage Publications.

Conflictos de intereses: el autor Ricardo Ayala declaró recibir un grant de European Comission. El autor Tomás Koch no declara relaciones en este documento.

\section{Correspondencia a:}

Ricardo A. Ayala

Korte Meer 5, B-9000 Gent, Belgium

E-mail: RicardoAlexis.AyalaValenzuela@UGent.be 